\title{
AUTOBIOGRAFIAS DOCENTES E A NECESSIDADE DO RETORNO DA VOZ FEMININA NA FORMAÇÃO DE PROFESSORES DE CIÊNCIAS
}

\author{
TEACHER AUTOBIOGRAPHIES AND THE NEED FOR THE RETURN OF THE \\ FEMALE VOICE IN THE TRAINING OF SCIENCE TEACHERS
}

\section{AUTOBIOGRAFÍAS DE MAESTROS Y LA NECESIDAD DE VUELVER LA VOZ FEMENINA EN LA CAPACITACIÓN PARA PROFESORES EN CIENCIAS}

\section{Cinara Calvi Anic* (D) 9}

Elizabeth Antônia Leonel de Moraes Martines ** (D) (9)

Amarildo Menezes Gonzaga*** (D) ()

\begin{abstract}
Resumo
O estudo aqui apresentado apoia-se no pressuposto de que a formação de professores implica a promoção de um contexto para o desenvolvimento nas dimensões intelectual, social e emocional de adultos por meio da reflexividade e do pensamento crítico advindos do ato de narrar sobre si. Com o objetivo de promover esse contexto, trazemos reflexões sobre a trajetória formativa de uma das pesquisadoras, a qual foi apresentada em uma tese doutoral juntamente com as narrativas autobiográficas de outros professores formadores de uma Instituição de Ensino Superior (IES) amazônica. Este artigo consiste em um recorte dessa pesquisa qualitativa e analisa a trajetória de formação da pesquisadora, que foi estruturada com base na Jornada do Herói/Heroína. Conclui-se que a formação, tanto da pesquisadora quanto dos professores formadores de licenciatura em Ciências Biológicas que participaram da pesquisa doutoral citada, foi situada em um paradigma positivista da ciência, no qual predomina a experimentação, a objetividade e a pesquisa quantitativa, ainda que estes atuem em ambientes onde há necessidade de se conciliar esta abordagem com o paradigma emergente de ciência, no qual há espaço para a pesquisa qualitativa, a subjetividade e as narrativas. Entende-se também, que há uma necessidade do retorno da voz feminina na ciência e na formação de professores, mas que este não é um processo fácil e rápido, que demanda muito esforço político, financeiro, institucional e pessoal, sendo que a reflexão proporcionada pela narrativa, especialmente aquela apoiada na Jornada do Herói é um caminho promissor nos processos de formação permanente de professores.
\end{abstract}

Palavras-chave: Formação de professores. Ensino de ciências. Pesquisa qualitativa. Jornada do Herói/Heroína. Feminilidade. \begin{tabular}{l} 
*Doutora em Educação Em Ciências e Matemática (UFMT). Professora dos cursos de licenciatura e Pós- \\
Graduação (PPGET e PROFET) do Instituto Federal de Educação, Ciência e Tecnologia do Amazonas (IFAM), \\
Manaus, Amazonas, Brasil. Endereço para correspondência: Rua Barão de Indaiá, 1025. Residencial Laranjeiras. \\
Casa 275. Flores, Manaus, AM, Brasil, cep: 69058-448. E-mail: cinara.anic @ifam.edu.br \\
${ }^{* *}$ Doutora em Psicologia Escolar e do Desenvolvimento Humano (USP). Professora aposentada da Universidade \\
Federal de Rondônia (UNIR), Porto Velho, Rondônia, Brasil. Endereço para correspondência: Av. Pedro Paulo \\
de Sousa, 1750, Residencial Felicitá, Bloco H, apto. 1306, Setor Goiânia 2, Goiânia, GO, Brasil, CEP: 74.663- \\
520. E-mail: bethmartines @ gmail.com \\
***Doutor em Educação (Universidade de Valladolid/Espanha). Professor dos cursos de licenciatura e Pós- \\
Graduação do Instituto Federal de Educação, Ciência e Tecnologia do Amazonas (IFAM), e do PPGET (IFAM) \\
Manaus, Amazonas, Brasil. Endereço para correspondência: Rua Gerânio, 341. Condomínio Nascentes do \\
Tarumã. Bairro Tarumã, Manaus, AM, Brasil, cep: 69041-010. E-mail: amarildo.gonzaga@ @ifam.edu.br \\
\hline \hline
\end{tabular} 


\begin{abstract}
This study is based on the assumption that teacher training implies the promotion of a context for development in the intellectual, social and emotional dimensions of adults, through reflexivity and critical thinking arising from the act of narrating about themselves. In order to promote this context, we bring reflections about the formative trajectory of one of the researchers, which was presented in a doctoral thesis together with autobiographical narratives of other teacher-trainers of an Amazonian Higher Education Institution (HEI). This article consists of an evaluation of this qualitative research and analyzes the trajectory of the researcher's education, which was structured based on the Hero/Heroine Journey. We conclude that the training of both the researcher and the graduate teachers in Biological Sciences that participated in the doctoral research cited, took place within a positivist paradigm of science, in which experimentation, objectivity and quantitative research predominate, even if they act in environments where there is a need to reconcile this approach with the emerging paradigm of science, in which there is room for qualitative research, subjectivity and narratives. It is also understood that there is a need for the return of the female voice in science and in teacher training, but that this is not an easy and fast process, which requires a lot of political, financial, institutional and personal effort, and that the reflection provided by narrative, especially the one supported by the Hero's Journey is a promising path in the processes of permanent teacher training.
\end{abstract}

Keywords: Teacher training. Science teaching. Qualitative research. Hero/Heroine Journey. Femininity.

\title{
RESUMEN
}

El presente estudio parte del supuesto de que la capacitación del profesorado implica la promoción de un contexto de desarrollo en las dimensiones intelectual, social y emocional de los adultos a través de la reflexividad y el pensamiento crítico que surgen del acto de narrar sobre uno mismo. Para promover ese contexto, traemos reflexiones sobre la trayectoria formativa de una de las investigadoras, quien fue presentada en una tesis doctoral junto con las narrativas autobiográficas de otros docentes que conformaron una Institución de Educación Superior Amazónica (ESA). Este artículo es un extracto de esa investigación cualitativa y analiza la trayectoria de formación del investigador, que se estructuró a partir de El Viaje del Héroe / Heroína. Se concluye que la capacitación, tanto del investigador como de los maestros de las Ciencias Biológicas que participaron en la investigación doctoral antes mencionada, se realizó dentro del paradigma positivista de la ciencia, aún prevalecen la experimentación, la objetividad y la investigación cuantitativa que actúan en entornos donde existe la necesidad de conciliar ese enfoque con el paradigma emergente de la ciencia, en el que hay espacio para la investigación cualitativa, la subjetividad y las narrativas. Es necesario el regreso de la voz femenina en la ciencia y en el grado de los maestros, pero eso no es un proceso fácil y rápido, por lo tanto exige mucho esfuerzo político, financiero, institucional y personal; allá la reflexión proporcionada por la narrativa, especialmente la sustentada por El Viaje del Héroe, es un camino prometedor en los procesos de capacitación contínua.

Palabras clave: Formación de profesores. Enseñanza de las ciencias. Investigación cualitativa. El viaje del héroe / heroína. Feminidad.

\section{INTRODUÇÃO}

A renovação no tratamento conferido à atividade docente a fim de compreendê-la articulada à pessoa do professor enquanto ser carregado de emoções, crenças e subjetividades, ocorreu especialmente no final dos anos 80 em vários países, quando surgiram vários estudos 
sobre a vida dos professores, suas carreiras e seu desenvolvimento profissional (NÓVOA, 2007). Essa abordagem de pesquisa-formação confere relevância à dimensão discursiva da individualidade, à forma com que os seres humanos vivenciam e atribuem significado ao mundo da vida, por meio da linguagem (BOLÍVAR, 2012).

Este trabalho é um ensaio construído a partir de uma tese de doutorado em que a história de vida de uma professora formadora de Licenciatura em Ciências Biológicas de uma Instituição de Ensino Superior (IES) amazônica foi registrada, analisada e estruturada segundo o modelo para análise de narrativas denominado "A Jornada do Herói” (ANIC; GONZAGA, 2019). Entende-se que a abordagem narrativa na perspectiva (auto)biográfica, como assinala Silva (2021), permite que o campo da subjetividade se articule ao espaço pessoal e social com as significações e ressignificações didáticas que ocorrem ao longo da profissionalização, trazendo novos sentidos e, consequentemente, novas práticas.

Deste estudo emergiram relações entre a feminilidade e a emergência da pesquisa qualitativa-interpretativa na formação de professores de Ciências/Biologia, bem como a necessidade de se integrar esta visão com a masculinidade e a pesquisa quantitativa/experimental na construção da identidade do professor de Ciências na contemporaneidade. Tal estudo pode representar um caminho para oportunizar reflexões acerca da necessária abertura para os diversos tipos de pesquisa, os quais devem ser abordados, discutidos e praticados na formação dos professores, especialmente de Ciências.

\section{REFERENCIAL TEÓRICO-METODOLÓGICO}

O conceito de formação docente adotado neste trabalho vincula-se à ideia de que a formação de professores implica a promoção de um contexto para o desenvolvimento nas dimensões intelectual, social e emocional (GARCIA, 1997). Por isso, Nóvoa (1997) argumenta que falar em formação significa considerar um trabalho de reflexão sobre os percursos da vida.

Foi utilizado o método biográfico a partir da autobiografia de uma das autoras, redigida durante a construção da tese de uma pesquisa doutoral que também fez uso de narrativas autobiográficas primárias recolhidas diretamente por um investigador no contexto de uma interação física, face a face (FERRAROTTI, 2010; SOUZA, 2006).

Assim, o corpus de análise neste trabalho é a autobiografia da pesquisadora-formadora (Autora 1) registrada na análise dos dados da pesquisa qualitativa desenvolvida durante o seu doutorado, na qual a mesma relata ter encontrado dificuldades em usar a pesquisa narrativa, 
uma vez que foi formada no contexto da pesquisa científica experimental das Ciências Biológicas.

A autobiografia foi construída utilizando-se como o modelo teórico a estrutura textual discursiva da Jornada do Herói/ Heroína (CAMPBELL, 1997), a qual explicita as recorrências de fases atravessadas por uma pessoa comum que se lança numa aventura e volta dela com outras percepções e significados, decorrentes de novas aprendizagens. Para Bertaux (2010), toda narrativa de vida apresenta elementos de informação e indícios de fenômenos situados nos mais diversos níveis, como a estruturação inicial da personalidade do sujeito, as aprendizagens culturais e profissionais, as transformações psíquicas, fenômenos culturais, histórico das relações dos sujeitos com o próximo, dentre outros.

Na carreira dos professores, por exemplo, há incidentes críticos (GOODSON, 2007), que podem afetar sua percepção e suas práticas profissionais. Daí, a importância de dar voz ao professor, uma vez que não é possível separar no professor seu eu pessoal do eu profissional, considerando uma profissão que é fortemente impregnada de valores e ideias.

A renovação no tratamento referente à pessoa do professor reflete as mudanças no interesse dos pesquisadores pelas novas abordagens nas ciências humanas, como as biografias, denotando o interesse pelo cotidiano, pelo pessoal, pelo privado, pelo familiar e por suas representações e apropriações (SOUZA, 2006). Josso (2002) também discorre sobre a emergência do que considera "[...] um novo horizonte teórico no campo da educação de adultos" (JOSSO, 2002, p. 14), a partir da proposição de uma nova abordagem de formação centrada no sujeito aprendente, partindo de uma metodologia de investigação-formação articulada às histórias de vida. Estudos como os de Cecim e Straforini (2018), Ventura e Cruz (2019), Silva (2018), dentre outros, pautam-se na escrita de narrativas autobiográficas como instrumentos de investigação-formação, elucidando a fecundidade deste método para a formação de professores em diversos contextos, como formação inicial e continuada, educação infantil, educação básica e superior.

Uma alternativa para analisar as autobiografias é a estrutura da Jornada do Herói proposta por Campbell (1997), que analisou narrativas míticas e foi adaptada por Vogler (2006) para o cinema. Martinez (2008) questiona a estruturação da Jornada para as histórias vividas por mulheres e propõem a Jornada da Heroína. Neste trabalho, utiliza-se uma síntese das três estruturas propostas por esses autores para descrever e analisar a trajetória de vida e a formação de uma das autoras (1).

Embora a Jornada do Herói/Heroína se apresente como uma estrutura, ela representa 
um mapa de direções, de possibilidades, que permite ao leitor que imerge na história de vida de um indivíduo relacioná-la à sua própria trajetória, tirando ensinamentos para sua própria existência. A Jornada do Herói/Heroína está organizada em etapas. Porém, essa sequência, necessariamente, não precisa ser linear, inclusive porque a vida não é linear: há momentos de dificuldades, de alegrias, de altos e baixos, vivências boas e vivências ruins. Ao percorrermos a trajetória do herói/heroína, clarifica-se o espaço tridimensional da narrativa preconizado por Clandinin e Connelly (2011), no qual o contexto social (interações pessoais e sociais), a temporalidade (passado, presente e futuro) e o lugar (situação) se imbricam, trazendo novos significados às nossas experiências.

\section{RESULTADOS E DISCUSSÃO}

Nesta seção, apresentamos a análise da história de vida de uma formadora de professores de Ciências Biológicas (Autora 1), tendo como estrutura a Jornada do Herói/Heroína, referente a sua trajetória de formação e a sua prática docente.

\subsection{A voz feminina e a Jornada do Herói/Heroína na pesquisa como formadora de professores de Biologia}

A estrutura textual da Jornada do Herói/Heroína, ao evidenciar o alinhamento do personagem principal (o herói/a heroína), mostra-se análoga aos pressupostos da abordagem narrativa, porque: a) considera o indivíduo contemporâneo como um produto de seus pensamentos, valores e qualidades pessoais; b) considera a teoria junguiana, que concebe o ser humano inserido num processo de individuação; c) considera o ser humano como parte integrante do paradigma da percepção ecológica profunda, referente ao não isolamento do ser humano no momento em que este faz parte de outras linhas de força maiores que podem influenciá-lo (MARTINEZ, 2008).

Tomando a formação de professores como objeto de pesquisa, constata-se a importância da subjetividade nesses estudos e reconhecemos, como Nóvoa (2007), que a prática docente se constitui da inter-relação entre duas dimensões, uma subjetiva e outra objetiva, que se confluem e definem a maneira de o professor planejar sua conduta docente e pessoal. Por isso, toda ação do professor é reflexo de seu próprio mundo cognitivo, isto é, suas intenções, seus propósitos e suas crenças, além das situações contextuais específicas.

Buscou-se apoio na narrativa, por permitir, conforme Rabelo (2011), a compreensão 
de como os docentes dão sentido ao seu trabalho, ao atuarem em seus contextos profissionais, além de poder, por si só, ser formativa devido à reflexão que ela desencadeia. A autora 1 admite nunca ter pensado, até seu ingresso no doutorado, no papel da narrativa como instrumento formativo, uma vez que sua cabeça, seu coração e seus pensamentos têm raízes positivistas, em que questões muito abstratas, sem possibilidade de comprovação experimental, eram vistas com ressalvas em relação à sua cientificidade. De fato, estudos como o de Alves e Mesquita (2015) observaram, dentre licenciandos em Química, as influências positivistas na sua formação, sobretudo na construção dos saberes a partir de bases quantitativas e experimentais, alicerçadas na neutralidade da Ciência. Os autores supracitados acrescentam que essas influências na formação de professores podem consolidar práticas docentes inadequadas, as quais enfatizam a experimentação e a ênfase no produto científico.

Quando a autora 1 rememora suas experiências e seus motivos pessoais, ainda na infância, para a escolha da profissão e, posteriormente, quando resgata sua trajetória formativa, conectando essas lembranças à sua atuação profissional, verifica-se que houve uma ressignificação do ser professor e do ser (ou não ser) pesquisador, uma vez que a formação na maior parte do tempo de escolarização se pautou na transmissão de conhecimentos.

O significado inicial de pesquisa educacional, em seu imaginário, dizia respeito a uma pesquisa que, por não pretender a verificação ou reprodução dos resultados, deixava dúvidas quanto à sua cientificidade, limitando-se a estudos com descrições de situações particulares ou ainda com recomendações para pesquisas futuras.

A estrutura da Jornada do Herói tem início com a partida de uma pessoa comum em busca de viver uma aventura, sendo que tal partida pode ocorrer por diversas razões, seja por uma inquietude e ansiedade do herói, ou pelo fato de ele responder a um chamado, uma tentação, um convite, do qual ele não pode declinar (VENTURA, LOSTADA, CRUZ, 2018). Na Jornada do Herói, a etapa do Chamado representa o momento em que algo se move dentro do herói, levando-o à necessidade de mudanças.

Em relação à trajetória formativa e profissional da pesquisadora, a formação inicial e o começo da carreira docente transcorreram sem os desafios típicos dessa etapa, pois a concepção de ciência moderna que subjazia à formação e à prática docente como professora de Ciências tornava tudo normal, sem muitos conflitos ou desafios. O Chamado só ocorreu mais tarde, em 2008, quando do ingresso no corpo docente no Instituto Federal de Educação, Ciência e Tecnologia do Amazonas (IFAM). Configuram-se como elementos que a levaram a aceitar o Chamado os desafios vivenciados com a orientação de alunos em Trabalho de 
Conclusão de Curso (TCC) e o desenvolvimento de projetos relacionados à área educacional, como o Programa Prodocência, vinculado à CAPES.

Esses desafios foram se articulando às antigas crenças e inquietações que já possuía antes do ingresso nessa instituição, considerando-se as reflexões sobre o período da formação inicial, especialmente em relação à formação em pesquisa e às implicações dessa formação na prática docente, desde sua atuação na Educação Básica.

A autora 1 recorda de seu ingresso no curso de Licenciatura Plena em Ciências Biológicas na Universidade Estadual Paulista (UNESP), Campus São José do Rio Preto, em 1992. A instituição ofertava o curso nas modalidades licenciatura e bacharelado, mas, ainda no vestibular, ela optou pela licenciatura pelo desejo manifestado desde a infância em ser professora. Ela se recorda também da participação voluntária, ainda na graduação, em projetos de iniciação científica nas áreas de Zoologia e Histologia, buscando a identificação com alguma subárea da Biologia sobre a qual aflorasse alguma afinidade para, posteriormente, seguir adiante nos estudos, considerando-se o desejo de também atuar no Ensino Superior.

Nesse período, alguns de seus formadores cursavam doutorado, outros eram mestres e outros já eram doutores. Porém, quando falavam em pesquisa científica, poucos mencionavam sobre a divulgação dos resultados, sobre a comunicação representar uma das etapas do processo de pesquisa cientifica. Na prática docente, pesquisar era uma ação ligada especialmente ao ato de buscar informações nos livros, ou seja, a conexão entre ensino e pesquisa não era clara, pois, por mais que esses professores tivessem experiência em pesquisa, essas experiências não eram compartilhadas com os alunos, ao menos não na sala de aula.

Sobre esse aspecto, o estudo conduzido por Lüdke (2009) ilustra a formação deficiente em pesquisa observada entre professores da Educação Básica ao relatarem que, durante sua formação inicial, não tiverem sequer uma disciplina de tratasse das questões da pesquisa, assim como ocorreu com a pesquisadora em sua formação inicial. Ela lembra que, nesse período, em nenhum momento houve contato com a pesquisa educacional, sendo a formação baseada na transmissão de conteúdos, com parcas oportunidades de desenvolvimento de projetos de pesquisa científica e/ou educacional.

Nesse contexto, a pesquisa não era tratada como um princípio educativo e científico, conforme preconizado por Galiazzi (2014). Portanto, é preciso que se recupere a atitude de pesquisa na formação inicial de professores, especialmente dos de ciências, assumindo-a como uma conduta estrutural, imprescindível para que sejamos professores no seu sentido 
pleno.

Nesse aspecto, é preciso salientar a relevância da atuação do professor formador como um dos fatores fundamentais na formação da identidade docente, tendo em vista que é ele quem representa uma das primeiras referências profissionais para os licenciandos (GARCIA, 1997).

A autora 1 reconhece que, em um momento crucial da formação profissional e da própria vida pessoal, não foi oportunizado o contato com a pesquisa educacional e isto também ocorreu com os demais formadores que participaram da pesquisa doutoral. Fica evidente a assertiva quando se associa a situação descrita ao posicionamento de Diniz-Pereira (2011), quando argumenta que um dos primeiros passos na direção da construção da identidade docente é assumir-se como educador, optando por um curso que o habilite para o exercício da profissão. A formação inicial assume, portanto, papel preponderante, uma vez que é nesse momento que o futuro professor, que já possui em seu imaginário sentimentos, crenças e modelos de docência trazidos de sua experiência como aluno, passa a ter contato com a atividade docente sob outra perspectiva, a docência como profissão, formalizada e fundamentada a partir de bases teóricas, epistemológicas e práticas.

Por isso, a investigação do trabalho do professor formador de professores é crucial, haja vista os novos desafios da contemporaneidade, os quais incluem as consequências vivenciadas no contexto pandêmico, a necessidade de articulação das tecnologias ao ensino e as novas configurações dos cursos de licenciatura advindas das novas diretrizes legais, como a Base Nacional Comum para Formação Inicial de Professores (BRASIL, 2019).

Ao dialogar com os teóricos e após o ingresso no IFAM, quando sentiu o Chamado, e no percurso do doutorado, a autora 1 certificou-se de que desenvolveu um novo sentido para a pesquisa educacional, descontruindo sua visão anterior que a julgava como uma pesquisa secundária que, na prática, não trazia muitas contribuições para o dia a dia do professor, diante das dificuldades operacionais do fazer docente (salas de aula lotadas, recursos didáticos precários) nem para o avanço do conhecimento científico.

De acordo com Gatti (2004), há necessidade de a universidade contar com professores pesquisadores, considerando que o ensino advém da investigação, de reflexões científicas e da importância do que chama de triangulação na formação e na ação, ou seja, uma articulação entre docência, pesquisa especializada e pesquisa sobre a ação docente.

Desde 1996, quando iniciou a docência, até 2005, quando ingressou como professora em um curso de Licenciatura, a autora 1 experimentou a docência no Ensino Fundamental e 
Médio. Lembra que esse período foi, no início, de muita tensão e questionamentos, pois não tinha nenhuma habilidade para lidar com os conflitos típicos dos adolescentes e, possivelmente, como seus professores formadores, reproduzia a prática de quem considerava serem os melhores professores, buscando desenvolver um trabalho de boa qualidade. Porém, em momento algum ela se questionou acerca de suas concepções de ciência ou de docência, atribuindo aos alunos, às suas famílias e/ou aos gestores da educação a culpa pelo que considera como indisciplina, falta de responsabilidade e de compromisso com a Educação.

Ao retomar sua trajetória e sua prática docente a pesquisadora, logo no início de sua carreira docente, optou por ingressar na pós-graduação por acreditar ser este o melhor caminho para atuar no Ensino Superior. Segundo ela, esse também foi um período complexo, pois não tinha clareza de qual área seguir, lembrando que desconhecia a existência de programas de pós-graduação na área da Educação.

Assim, em 1998, ingressou no curso de Mestrado em Ecologia - Ecossistemas Aquáticos e Terrestres oferecido pela Universidade de São Paulo. O período no mestrado possibilitou-lhe as primeiras experiências com a pesquisa científica pois, até então, nunca havia construído um projeto de pesquisa nem havia tido contato com qualquer leitura ou orientação sobre o desenvolvimento de projetos dessa natureza, tampouco estava habituada com a leitura de artigos científicos. Todas as atividades relativas à construção e ao desenvolvimento da pesquisa foram realizadas a partir de buscas, leituras e discussões com os colegas, além das orientações do professor orientador, que priorizava a parte experimental da pesquisa, não fazendo questionamentos a respeito de sua estruturação e construção epistemológica.

Durante o mestrado a pesquisadora retomou suas atividades docentes na Educação Básica. Essa retomada representou um novo período de angústias pois, dessa vez, a atuação era em escolas da rede particular, exigentes na necessidade do controle sobre a indisciplina dos alunos. Porém, ela considera que desenvolveu um trabalho pedagógico de boa qualidade, sob a supervisão rigorosa de um pedagogo para auxiliar os professores. Esse papel mediador foi uma nova descoberta, pois, até aquele momento, suas percepções sobre os pedagogos referiam-se a profissionais que desenvolviam atividades técnicas, burocráticas, acompanhamento e supervisão de documentos etc.

Em 2005, já em Manaus, a autora 1 se torna formadora no Ensino Superior, num curso de licenciatura em Ciências Biológicas de uma universidade particular. Considera que este foi um período de intenso aprendizado pois, ao mesmo tempo em que exercia a docência, 
assumiu a coordenação do referido curso o qual, no mesmo ano, recebeu a visita do Ministério da Educação (MEC) para reconhecimento e avaliação. Foi nessa ocasião que ocorreu o primeiro contato da formadora com a pesquisa na área de Educação e a legislação educacional de forma sistematizada e com bases teóricas, além da legislação específica para a formação do biólogo, haja vista estar na coordenação de um curso em processo de avaliação e reconhecimento. Tal estudo trouxe muitas inquietações a ela, pois sua primeira impressão era de que esses documentos legais não se articulavam, nem deixavam claro qual o perfil do egresso de um curso de licenciatura.

Ao ingressar como professora no IFAM, em janeiro de 2008, já tinha uma experiência de 3 anos em um curso de licenciatura, inclusive com orientação de Estágio Supervisionado, além da experiência anterior na Educação Básica. Porém, não tinha um contato teóricometodológico mais aprofundado com a pesquisa educacional. Como nunca havia tido aulas de Filosofia da Ciência, Metodologia Científica ou Metodologia da Pesquisa, não conhecia, do ponto de vista teórico/epistemológico, os procedimentos básicos da pesquisa, como delimitação de objeto de estudo, problema, questões norteadoras. A orientação que prestava aos alunos tinha um caráter operacional, baseado nas suas próprias experiências como professora e como aluna de mestrado.

Com base em Tardif (2014), naquela ação era mobilizado, especialmente, o saber disciplinar, que diz respeito ao conhecimento do conteúdo a ser ensinado e o saber da experiência, que nasce dela e por ela são validados.

Ao iniciar a leitura de artigos científicos da pesquisa educacional, a autora 1 relata que sua primeira reação era de descrença, pois não conseguia visualizar dados, tampouco uma descrição clara da metodologia utilizada. As leituras pareciam redundantes e inconclusivas, limitando-se ao plano das recomendações para o desenvolvimento de pesquisas futuras. De fato, alguns autores como Gamboa (2012) atentam para a fragilidade teórica, metodológica e epistemológica de muitas pesquisas na área da Educação. Reportando-se ao período em que ingressou no IFAM, ela relata ter assumido a coordenação do curso de Licenciatura em Ciências Biológicas, coincidindo com o período em que aquele curso passaria por uma reformulação de sua matriz curricular, tendo em vista as recomendações feitas pela comissão avaliadora do MEC, na ocasião de visita técnica, para reconhecimento do curso. O curso em questão foi totalmente reformulado, constando, no perfil do egresso, a formação do professor pesquisador.

O processo de reformulação foi liderado pela coordenação de curso juntamente com 
uma pedagoga, que elaborou e escreveu a parte pedagógica. Aos professores das áreas específicas coube a tarefa de se reunirem para reestruturação da matriz curricular no que se referia à sua ordenação, delimitação da carga horária e nomenclatura das disciplinas. Nesse processo não foi efetivado o diálogo entre as disciplinas especificas e pedagógicas e, naquele momento, a pesquisadora ressalta sua impressão de ainda não ter despertado para a necessidade e importância da articulação dessas disciplinas, tampouco do modelo de formação de professores (professor pesquisador e professor reflexivo) que, a partir de então, nortearia os objetivos do curso.

Esse momento representou, portanto, o início do contato da autora 1 com a tendência professor pesquisador, não havendo, entretanto, nenhuma referência teórica a respeito. Acreditava, até esse momento, que o fato de pesquisar para preparar as suas aulas era suficiente para tornar um professor em professor pesquisador. Posteriormente, com o lançamento do Edital da Coordenação de Aperfeiçoamento do Pessoal do Ensino Superior (CAPES) para o Programa Institucional de Bolsa de Iniciação à Docência (PIBID), a formadora foi instigada a intensificar suas leituras na pesquisa educacional a fim de criar um projeto interno para concorrer ao referido edital. Paralelamente, ela desenvolvia atividades de orientação aos alunos pelo Programa Prodocência ${ }^{1}$.

Os novos desafios impostos por força da inserção no Prodocência e no PIBID, da necessidade de orientação dos alunos em pesquisas educacionais, de compreensão dos novos conceitos que norteavam o curso de licenciatura em que atuava, fizeram a formadora aceitar o Chamado, isto é, buscar o curso de pós-graduação na área de Ensino de Ciências e Matemática pois, não tendo nenhuma familiaridade com as pesquisas referentes àquela área do conhecimento, a orientação aos alunos e o desenvolvimento dos projetos de iniciação à docência certamente estavam comprometidos.

Tendo aceitado o Chamado (CAMPBELL, 1997), atravessa-se o Primeiro Limiar quando, na Jornada do Herói/Heroína, após o contato com o Mentor (alguém que o estimula a aceitar o Chamado) implementa-se a mudança. Nessa fase, o protagonista ainda tem dúvidas em relação à sua escolha: pode ser preciso renunciar a algo difícil, para que possa iniciar uma

\footnotetext{
${ }^{1}$ O Programa de Consolidação das Licenciaturas (PRODOSCÊNCIA) foi desenvolvido pelas Instituições de Ensino Superior (IES), com financiamento do Ministério da Educação, Secretaria de Ensino Superior visando ampliar a qualidade das ações voltadas à formação de professores para a educação básica. Foi lançado em 2006, através de edital ao qual as IES submetiam projetos. Disponível em http://portal.mec.gov.br/sesu/arquivos/pdf/Prodocencia/edital_011_2006.pdf. Acessado em: 28/06/2021.
} 
nova fase da vida. Mas, essa escolha certamente o colocará, futuramente, em um nível de aprendizado emocional e intelectual muito mais ampliado (MARTINEZ, 2008).

$\mathrm{Na}$ trajetória formativa da autora 1, a Travessia do Limiar se efetiva com sua decisão em participar da seleção para o doutorado, tendo em vista as dificuldades próprias de quem não está habituado a ler e discutir pesquisas, artigos construídos sob outra abordagem, mas decidiu, com o incentivo de alguns colegas e futuro orientador (Mentor) atravessar o limiar e lançar-se na aventura, certa de que poderia melhorar sua prática, sua formação e sua própria vida com as novas descobertas, abrindo o coração e a mente para novos desafios e novas formas de ver o mundo.

Atravessado o Primeiro Limiar, o herói/a heroína segue em sua trajetória podendo encontrar os Guardiões do Limiar, ou seja, pessoas prontas a desencorajá-lo/a a ir além dos limites aceitos pela sociedade, testando o comprometimento real do protagonista com o novo desafio. Nessa etapa, a autora 1 considera os Guardiões do Limiar os membros da banca examinadora da seleção, pautando-se em Vogler (2006, p. 134) que afirma que é possível vencermos os guardiões ao nos convencermos de que "[...] o que parece um obstáculo pode ser, no fundo, a maneira de atravessar o Limiar".

Prosseguindo sua passagem pelo primeiro limiar, a autora 1 inicia, em janeiro de 2013, o doutorado em Ensino de Ciências e Matemática da Rede Amazônica de Educação em Ciências e Matemática (REAMEC). Esse período correspondeu à etapa da Jornada do Herói denominada Ventre da Baleia, isto é, uma fase de recolhimento, de internalização quando, ao invés de conquistar ou aplacar a força do limiar, o herói é jogado no desconhecido sendo, portanto, uma fase de reclusão. Martinez (2008), quando propõe a jornada da Heroína a chama de Caverna. O desconhecido e o temor se revelam para a pesquisadora, quando ela se depara com textos e leituras advindas das primeiras disciplinas cursadas, com temáticas referentes à Filosofia, bases epistemológicas da ciência, totalmente desconhecidas até então.

Tal desafio somava-se às outras obrigações, como cursar essas disciplinas em serviço por não ter se afastado de suas atividades como docente. Nessa fase, ela ressalta que a heterogeneidade da turma se mostrou positiva, no sentido de ter como colegas de turma pessoas com formações iniciais variadas, com outros olhares, outras visões de mundo. A maioria deles tinha formação (inicial ou continuada) em cursos da área da Educação, o que lhes permitiam esclarecer dúvidas, indicar outras leituras, ainda que se mostrassem tão inseguros quanto a própria pesquisadora. O clima nas aulas era de descontração, empatia e liberdade para compartilhamento das incertezas e angústias. 
Passado algum tempo, ela reconhece não só nos colegas de turma, mas também no grupo de pesquisa no qual se inseriu em sua IES e, especialmente, em seu orientador, a figura do Mentor, no sentido de representarem pessoas mais experientes que orientam o herói/a heroína sobre os desafios da Jornada, incentivando-o/a a aceitar a aventura (MARTINEZ, 2008).

Temas como Tendências na Formação de Professores, Bases Epistemológicas para a Educação, Bases Legais para a Formação de Professores e de Biólogos, Metodologia da Pesquisa Qualitativa passaram a ser recorrentes nas leituras da pesquisadora, fazendo surgir questionamentos que, esclarecidos, possibilitaram-lhe um novo olhar para a pesquisa educacional: a velha figura de uma pesquisa realizada sem uma aplicação prática efetiva, que se restringia no plano teórico, passa a adquirir um novo sentido no momento em que percebe como é possível sua articulação com a prática, na medida em que busca solucionar problemas advindos dessa prática, sendo esse o ponto de partida para a ação. No Ventre da Baleia (ou na Caverna) busca-se as bases teóricas para fundamentar sua pesquisa de doutoramento e sua prática como formadora de professores de Biologia para a educação básica.

Seguindo a Jornada do Herói, o Encontro com a Deusa (ou a Mulher como tentação) representa a fase na qual o herói unifica os padrões arquetípicos do masculino e do feminino. O psicólogo Jung defendia que, biologicamente, tanto o sexo masculino quanto o feminino abrigam características do sexo oposto e, para que a personalidade esteja em equilíbrio, essas características devem expressar-se na consciência e manifestar-se no comportamento. Campbell (1997), que se utilizou das ideias de Jung na elucidação da Jornada do Herói, afirma que a Deusa influencia todas as etapas da existência, unindo o bom e o mau: a mulher representa, na linguagem pictórica da mitologia, a totalidade do que pode ser conhecido. $\mathrm{O}$ herói é aquele que aprende. À medida que ele progride, na lenta iniciação que é a vida, a forma da deusa passa, aos seus olhos, por uma série de transfigurações.

[...] Ela o atrai e guia e lhe pede que rompa os grilhões que o prendem. E se ele puder alcançar-lhe a importância, os dois, o sujeito do conhecimento e o seu objeto, serão libertados de todas as limitações [...] O herói que puder considerá-la tal como ela é, sem comoção indevida, mas com a gentileza e a segurança que ela requer, traz em si o potencial do rei, do deus encarnado, do seu mundo criado (CAMPBELL, 1997, p. 66).

Na concepção junguiana, essa figura é projetada inicialmente na mãe, passando, posteriormente, para outras figuras que exercem funções protetoras, como professoras, irmãs e esposas. Porém, em determinado momento, é necessário que o homem abandone suas imagens femininas idealizadas, para que possa livrar-se de imagens maternas ocasionalmente 
inadequadas, como uma mãe ausente ou repressora, as quais podem interferir nos seus relacionamentos quando adulto.

Para Murdock (1990), citada por Martinez (2008), na contemporaneidade o desafio que se impõe às mulheres é promover a religação com sua natureza feminina, uma vez que passam pela competição e necessidade de formação profissional e construção de uma carreira fora do lar. Por isso, é necessário abstrairmos o lado racional e objetivo para darmos vazão à contraparte feminina, subjetiva, intuitiva e criativa. Este processo permite à mulher ir formando sua identidade: desvincula-se da mãe para nortear-se pelo perfil paterno ou outro mentor masculino. Em seguida, passa por provações, como as pressões em realizar as demandas sociais e a conciliação da busca do êxito profissional com a família. Ao final da Jornada, quando esta é bem-sucedida, a mulher é reconduzida à mãe, integrando o masculino e o feminino (MARTINEZ, 2008).

Em sua pesquisa, a autora 1 considera que o Encontro com a Deusa se fez presente quando ela adotou uma postura de abertura da mente e reconheceu a pesquisa qualitativa, especialmente a abordagem narrativa, após muitas leituras e discussões com os mentores (incluindo-se aqui a autora 2 da banca do Exame de Qualificação), como uma forma válida de pesquisa que, ainda que permita aflorar as emoções e fraquezas, atribuídos tipicamente à natureza feminina, não perde a cientificidade.

Nessa perspectiva, o Encontro com a Deusa se concretiza no instante em que a pesquisadora assume o desafio de escrever sua tese na forma narrativa, utilizando a Jornada do Herói/Heroína, incluindo todas as provações que perpassam essa escrita, visando uma aprovação pelas bancas de qualificação e defesa.

A autora 1 vislumbra a efetivação da etapa A Mulher como Tentação quando se sente tentada a assumir a escrita e a estruturação de sua pesquisa na abordagem narrativa, se desapegando de suas crenças e práticas pautadas na perspectiva positivista. Nesse paradigma podemos reconhecer características tipicamente masculinas como a objetividade, dado o caráter prático do positivismo ao privilegiar a abordagem metodológica empírico-analítica, com a verificação de hipóteses geralmente testadas com base estatística e a busca de resultados generalizáveis. A Mulher aqui é representada pela abordagem narrativa, calcada no paradigma interpretativo, que não objetiva alcançar produtos, mas compreender o processo, o fenômeno em estudo, dando voz à consciência, às crenças, às subjetividades. Dar voz e permitir o emergir da subjetividade no processo de pesquisa significa aceitar a exposição de nossas fraquezas, de nossas frustações, das dificuldades enfrentadas no processo, deixando a 
feminilidade aflorar, numa sociedade machista e competitiva, através da solidariedade, da empatia, do cuidado consigo, com o próximo e com o meio.

A pesquisadora tem ciência de que é fruto de uma formação alicerçada no positivismo e, ao se ver na necessidade de reavaliar suas crenças e valores para se permitir um novo olhar sobre a pesquisa, significou encontrar-se com a Deusa, com a mulher, com a narrativa e sua poesia. Ao promover essa abertura, ela efetiva a etapa denominada Sintonia com o Pai, isto é, reconhece a abordagem quantitativa, masculina, objetiva, pragmática, como uma forma complementar à abordagem qualitativa, feminina, poética, sensível, não no sentido de atribuir maior valor a uma ou outra, mas no sentido e com a intenção de integrá-las, adequando-as e tornando-as coerentes aos objetivos educacionais ou da pesquisa que se pretende realizar.

Após realizar a Sintonia com o Pai, chega-se à etapa da Jornada do Herói/Heroína chamada de Apoteose ou Grande Conquista, quando o herói se torna livre para sedimentar a mudança de seu nível de consciência. Após a defesa da tese (primeira comunicação dos resultados aos pares da Banca Examinadora do Doutorado), chega a hora de compartilhar o conhecimento construído com o público em geral, através de comunicação em eventos, em sala de aula, da publicação de capítulos de livros e de artigos, como este, para ampliar o diálogo com outros formadores de professores de Ciências Biológicas.

É necessário também implementar mudanças nos currículos das licenciaturas, uma vez que, chegar a esse ponto na formação de professores para o ensino de Ciências, certamente exigirá uma verdadeira mudança cultural, que já está em jogo, com as atuais política de formação de professores.

\subsection{A integração feminino-masculino: diferentes abordagens de pesquisa na formação de professores de Ciências}

Para descrever como foi possível internalizar a complementaridade das pesquisas qualitativas e quantitativas foi preciso, inicialmente, que a autora 1 compreendesse as especificidades da pesquisa em Educação enquanto prática social humana e histórica. Assim, por sugestões dos Mentores que lhe acompanharam na construção da tese, iniciaram-se as leituras de obras que tratam da metodologia da pesquisa em Educação, como as de Gamboa (2012) e Ghedin e Franco (2011). Esse novo olhar não poderá ser apreendido por modelos metodológicos que buscam uma padronização, um congelamento dos momentos dessa prática humana, o que não é simples, haja vista a constatação de Ghedin e Franco (2011) de que a tradição positivista nos deixou o legado de que somente aquilo que pode ser comprovado e 
testado empiricamente é verdadeiro.

A pesquisadora reconhece que não desenvolveu essa nova concepção de pesquisa rapidamente e quando, enfim, ela acredita ter alcançado a clareza da especificidade da Educação, foi necessário efetivar, como preconiza Gamboa (2012), o relacionamento entre as técnicas que seriam utilizadas na pesquisa, os métodos e os procedimentos com seus correspondentes pressupostos teóricos e epistemológicos.

Entende-se, como Ghedin e Franco (2011), a metodologia utilizada como um processo organizado em torno de um quadro de referências decorrentes de atitudes e de crenças, que se configuram como visões de mundo, e não como um protocolo de regras e procedimentos a serem seguidos. $\mathrm{O}$ fato da sua formação ter se pautado nos princípios positivistas a levavam a pensar, inicialmente, na necessidade de se apoiar na abordagem quantitativa; porém, a todo momento, desde o início das disciplinas no doutorado, a pesquisadora pensava na inadequação desta para seus propósitos, uma vez que já tinha algumas ideias vagas sobre a pesquisa em Educação e algumas técnicas aqui utilizadas.

Tornou-se claro, enfim, que a abordagem quantitativa não representa uma oposição à abordagem qualitativa, mas a combinação de ambas, quando cabível, pode conferir maior enriquecimento à investigação. Ademais, em relação à formação de professores de ciências, é imprescindível que os licenciandos tenham contato com textos tanto de pesquisas realizadas em uma especialidade (geralmente quantitativas e ou experimental) quanto com artigos de pesquisas qualitativas, como estudos de casos bem sucedidos em Educação, sobre a prática docente (professor-pesquisador), bem como o uso de narrativas para desenvolver a identidade docente, o conhecimento sobre a história da ciência e da vida de cientistas importantes ou de pessoas comuns da comunidade, lembrando ainda do caráter formativo do ato de narrar em si (SOUZA, 2006).

Ao compreender e aceitar a complementaridade das abordagens qualitativa e quantitativa, integra-se o rigor e a objetividade que caracterizam as pesquisas quantitativas, isto é, os atributos masculinos, com a valorização da subjetividade e da integração com o objeto de estudo, próprias da abordagem qualitativa. Entendemos que é necessário aos licenciandos de Ciências Biológicas desenvolverem tanto o pensamento narrativo como o pensamento paradigmático, apoiando-nos em Bruner (2001), que caracteriza o pensar paradigmático baseando-se em sua preocupação na busca da verdade independente do contexto. O pensar narrativo, por sua vez, é qualitativamente diferente, pois está centrado em sentimentos, vivências e ações que dependem de contextos específicos. 


\section{Considerações Finais}

O objetivo deste trabalho foi refletir sobre a trajetória formativa de uma das pesquisadoras (1) a qual, em sua pesquisa doutoral que originou este estudo, traz questões relacionadas às subjetividades na formação de professores e a formação na e para a pesquisa. Com base nos pressupostos das narrativas autobiográficas, utilizou-se a estrutura da Jornada do Herói/Heroína para organizar essa trajetória formativa, oportunizando aos autores reflexões sobre o processo de formação de professores por eles vivenciados, no qual a pesquisa quantitativa, experimental, de viés positivista, foi (e continua sendo) hegemônica na graduação e no mestrado.

Quando a autora 1 se vê desafiada a fazer uso da pesquisa qualitativa, especialmente da modalidade narrativa, no seu processo de formação permanente quando ingressa no doutorado, ela encontra dificuldades e coloca muitas objeções sobre sua validade científica, resistindo ao seu uso. Foram necessárias muitas leituras de teses, de artigos, de manuais de metodologia científica e discussões nas disciplinas do doutorado, bem como com o orientador e a banca de qualificação e defesa, para que seus preconceitos e resistências se desfizessem e ela passasse a ver com mais clareza as concepções de ciência, sua natureza humana e histórica, que sofrem influências políticas, econômicas, culturais e sociais, sendo que a neutralidade e a objetividade pretendidas pelo positivismo, estão longe do almejado por seus defensores.

A Jornada do Herói/Heroína também ajudou os autores a perceberem que a pesquisa qualitativa representa o retorno da voz feminina na ciência, correspondendo na estrutura do mito, ao encontro em que o herói é tentado pela Mulher (o arquétipo feminino) ou onde a heroína se encontra com a Deusa, integrando o masculino e o feminino. Em sua pesquisa, a autora 1 considera que o Encontro com a Deusa se fez presente quando ela reconhece após muitas leituras e discussões com os mentores, a pesquisa qualitativa, especialmente a abordagem narrativa, como uma forma válida de pesquisa que, ainda que permita aflorar as emoções e fraquezas, atribuídos tipicamente à natureza feminina, não perde a cientificidade.

A Mulher aqui é representada pela abordagem narrativa, calcada no paradigma interpretativo, que não objetiva alcançar produtos, mas compreender o processo, o fenômeno em estudo, dando voz à consciência, às crenças, às subjetividades. Dar voz e permitir o emergir da subjetividade no processo da pesquisa significa permitirmo-nos expormos nossas fraquezas, nossas frustações, deixando nossa feminilidade aflorar, numa sociedade machista e 
competitiva.

A proposta do uso tanto das pesquisas quantitativas/experimentais como de pesquisa qualitativa na Educação corresponde à etapa chamada de Sintonia com o Pai na Jornada do Herói/Heroína, isto é, reconhece-se a abordagem quantitativa, masculina, objetiva, pragmática, como uma forma complementar à abordagem qualitativa, feminina, poética, sensível, não no sentido de atribuir maior valor a uma ou outra, mas com a intenção de integrá-las, adequando-as ao momento da formação e aos objetivos educacionais ou da pesquisa que se pretende realizar.

Conclui-se que a formação dos formadores das licenciaturas da área se deu dentro de um paradigma positivista da ciência, no qual predomina a experimentação, a objetividade e a pesquisa quantitativa, mas, que atuam em ambientes em que há necessidade de se conciliar esta abordagem com o paradigma emergente de ciência, no qual há espaço para a pesquisa qualitativa, a subjetividade e as narrativas. Entende-se também, que há uma necessidade do retorno da voz feminina na ciência e na formação de professores, mas que este não é um processo fácil e rápido, que demanda muito esforço político, financeiro, institucional e pessoal, sendo que a reflexão proporcionada pela narrativa, especialmente aquela apoiada na Jornada do Herói é um caminho promissor nos processos de formação permanente de professores.

Espera-se que estas reflexões e análises possam contribuir para que outros agentes educacionais se interroguem, reflitam e se posicionem diante da excessiva voz masculina na sociedade, na ciência e na formação de professores, para que ela seja equilibrada pelo retorno e valorização da voz feminina e de características tão importantes na sociedade, neste momento em que as reformulações curriculares das licenciaturas se fazem necessárias diante das novas diretrizes para formação de professores para a educação básica.

\section{REFERÊNCIAS}

ALVES, D. A.; MESQUITA, N. A. S. Influências Positivistas na formação de professores de Química no Instituto Federal Goiano. In: Encontro Nacional de Pesquisa em Educação em Ciências. Anais do X ENPEC.- Encontro Nacional de Pesquisa em Educação em Ciências, v. 10, p. 1-8, 2015. Disponível em: http://www.abrapecnet.org.br/enpec/xenpec/anais2015/resumos/R0310-1.PDF. Acesso em: 03 nov. 2021.

ANIC, C.C.; GONZAGA, A. M. A “Jornada do Herói” como possibilidade para estruturação e análise de narrativas de professores. In: AZEVEDO, R. O. M.; GUERREIRO, E. M. B. R.; PACHECO, M. L. T. (Org). Formação de professores em diferentes perspectivas. Curitiba: 
Appris, 2019. Disponível em: $\quad$ https://books.google.com.br/books?hl=ptBR\&lr=\&id=pfguEAAAQBAJ\&oi=fnd\&pg $=$ PT11\&dq=jornada + do + heroi $\&$ ots $=q$ PkLGHZA O5\&sig=spT6zMiwtyuUUc_45mrnbrnnibI\#v=onepage\&q\&f=false. Acesso em: 03 nov. 2021.

BERTAUX, D. Narrativas de vida: a pesquisa e seus métodos. 2. ed. São Paulo: Paulus, 2010. 167 p.

BOLÍVAR, A. Dimensiones epistemológicas y metodológicas de la investigación (auto)biográfica. In: ABRAAO, M. H. M.; PASSEGGI, M.C. (Org). Dimensões epistemológicas e metodológicas da pesquisa (auto) biográfica/ Tomo I. Natal: EDUFRN; Porto Alegre: EDIPUCRS; Salvador: EDUNEB, 2012. p. 27-70.

BRASIL, Ministério da Educação. Resolução CNE/CP N 2, de 20 de dezembro de 2019. Define as Diretrizes Curriculares Nacionais para a Formação Inicial de Professores para a Educação Básica e institui a Base Nacional Comum para a Formação Inicial de Professores da Educação Básica (BNC-Formação).Brasília: 2019. Disponível em: http://portal.mec.gov.br/docman/dezembro-2019-pdf/135951-rcp002-19/file. Acesso em: 28 out. 2021 .

BRUNER, J. A cultura da educação. Porto Alegre: ArtMed, 2001.

CAMPBELL, J. O herói de mil faces. São Paulo: Cultrix/ Pensamento. 1997.

CECIN, J. S. R. ; STRAFORINI, R. Narrativa autobiográfica e formação docente em Geografia. Reconstruindo percursos formativos a partir da narrativa da experiência. Jataí, Itinerarius Reflectionis, v. 14, n. 2, p. 01-18, 2018. Disponível em: https://www.revistas.ufg.br/rir/article/view/52725. Acesso em: 01 nov. 2021.

CLANDININ, D. J; CONNELLY, F. M. Pesquisa Narrativa: experiência e história em pesquisa qualitativa. Uberlândia, EDUFU, 2011.

DINIZ-PEREIRA, J. E. O ovo ou a galinha: a crise da profissão docente e a aparente falta de perspectiva para a educação brasileira. Revista Brasileira de Estudos Pedagógicos, Brasília, v. 92, n. 230, p. 34-51, jan./abr., 2011.

FERRAROTTI, F. Sobre a autonomia do método biográfico. In: NÓVOA, A.; FINGER, M. (Orgs.). O método (auto)biográfico e a formação. Lisboa: Departamento de Recursos Humanos/ Ministério da Saúde. 2010. p. 31-58.

GALIAZZI, M. C. Educar pela Pesquisa: Ambiente de Formação de Professores de Ciências. Ijuí: Unijuí, 2014. 288 p 
GAMBOA, S. S. Pesquisa em educação: métodos e epistemologias. 2 ed. Chapecó: Argos, 2012.

GARCIA, C. M. A formação de professores: algumas notas sobre sua história, ideologia e potencial. In: In: NÓVOA. A. (Org.). Os Professores e a sua Formação. 3 ed. Lisboa: Publicações Dom Quixote. Instituto de Inovação Educacional, 1997. p. 93-114.

GATTI, B. A. Formação do professor pesquisador para o Ensino Superior: desafios. In: BARBOSA, R. L. L. (Org.). Trajetórias e perspectivas da formação de educadores. São Paulo: UNESP, 2004. p.433-441.

GHEDIN, E.; FRANCO, M. A. S. Questões de método na construção da pesquisa em educação. São Paulo: Cortez, 2011.

GOODSON, I. F. Dar voz ao professor: as histórias de vida dos professores e o seu desenvolvimento profissional. In: NÓVOA, A (Org.). Vidas de professores. Porto: Porto Editora, 2007, p. 63-78.

JOSSO, M. C. Experiências de vida e formação. Lisboa: Educa, 2002.

LÜDKE, M (Coord.). O que conta como pesquisa? São Paulo: Cortez, 2009.

MARTINEZ, M. Jornada do herói: a estrutura narrativa mítica na construção das histórias de vida em jornalismo. São Paulo: Annablume, 2008.

NÓVOA. A. (Org.). Os Professores e a sua Formação. 3 ed. Lisboa: Publicações Dom Quixote. Instituto de Inovação Educacional, 1997.

NÓVOA, A. Vida de professores. Portugal: Porto Editora, 2007.

SILVA, R. M. O. O memorial autobiográfico como nova possibilidade didática nos processos de formação docente de professores da Educação Infantil. Ensino em Perspectivas, Fortaleza, v. 2, n. 2, p. 1-16, 2021.

RABELO, A. O. A importância da investigação narrativa na educação. Educação \& Sociedade, Campinas, v. 32, n. 114, p. 171-188, jan.-mar. 2011. 
SOUZA, E. C. A arte de contar e trocar experiências: reflexões teórico-metodológicas sobre história de vida em formação. Revista Educação em Questão, Natal, v. 25, n. 11, p. 22-39, jan./abr. 2006.

TARDIF, M. Saberes docentes e formação profissional. $7^{\text {a }}$ ed. Petrópolis, RJ: Vozes, 2014.

VENTURA, L.; LOSTADA; L. R.; CRUZ, D. M. A formação continuada de educadores a partir da Jornada do Herói: narrativas autobiográficas em foco. In: XV Congresso Brasileiro de Ensino Superior à Distância. IV Congresso Internacional de Educação Superior à Distância. Natal, 2018. Disponível em: https://esud2018.ufrn.br/wpcontent/uploads/187109_1ok.pdf. Acesso em: 03 nov. 2021.

VENTURA, L.; CRUZ, D. M. Metodologia de narrativas autobiográficas na formação de educadores. Revista Diálogo Educacional, Curitiba, v. 19, n. 60, p. 426-446, jan./mar. 2019. Disponível em: https://periodicos.pucpr.br/index.php/dialogoeducacional/article/view/23455. Acesso em: 01 nov. 2021.

VOGLER, C. A jornada do escritor: estruturas míticas para escritores. $2^{\mathrm{a}}$ ed. Rio de Janeiro : Nova Fronteira, 2006.

\section{APÊNDICE 1}

\section{AGRADECIMENTOS}

Não se aplica.

FINANCIAMENTO

Não houve financiamento

\section{CONTRIBUIÇÕES DE AUTORIA}

Resumo/Abstract/Resumen: Cinara Calvi Anic.

Introdução: Cinara Calvi Anic/ Elizabeth Antônia Leonel de Moraes Martines/Amarildo Menezes Gonzaga

Referencial teórico: Cinara Calvi Anic/ Elizabeth Antônia Leonel de Moraes Martines/ Amarildo Menezes Gonzaga

Análise de dados: Cinara Calvi Anic/ Elizabeth Antônia Leonel de Moraes Martines/Amarildo Menezes Gonzaga

Discussão dos resultados: Cinara Calvi Anic/ Elizabeth Antônia Leonel de Moraes Martines,/Amarildo Menezes Gonzaga

Conclusão e considerações finais: Cinara Calvi Anic/ Elizabeth Antônia Leonel de Moraes Martines/Amarildo Menezes Gonzaga

Referências: Cinara Calvi Anic/ Elizabeth Antônia Leonel de Moraes Martines.

Revisão do manuscrito: Cinara Calvi Anic/ Elizabeth Antônia Leonel de Moraes Martines/Amarildo Menezes Gonzaga

Aprovação da versão final publicada: Cinara Calvi Anic/ Elizabeth Antônia Leonel de Moraes Martines/ Amarildo Menezes Gonzaga

\section{CONFLITOS DE INTERESSE}

Os autores declararam não haver nenhum conflito de interesse de ordem pessoal, comercial, acadêmico, político e financeiro referente a este manuscrito. 


\section{DISPONIBILIDADE DE DADOS DE PESQUISA}

Nós, autores do manuscrito, disponibilizamos os dados da pesquisa aqui publicados. Este artigo foi derivado de uma pesquisa doutoral de autoria de Cinara Calvi Anic, sob orientação de Amarildo Menezes Gonzaga, defendida em novembro de 2016 e vinculada ao programa de pós-graduação da Rede Amazônica de Educação em Ensino de Ciências e Matemática- REAMEC. Além deste artigo, a referida tese deu origem a um capítulo de livro: ANIC, C.C.; GONZAGA, A. M. A "Jornada do Herói” como possibilidade para estruturação e análise de narrativas de professores. In: AZEVEDO, R. O. M.; GUERREIRO, E. M. B. R.; PACHECO, M. L. T. (Org). Formação de professores em diferentes perspectivas. Curitiba: Appris, 2019.

\section{CONSENTIMENTO DE USO DE IMAGEM}

Não se aplica.

\section{APROVAÇÃO DE COMITÊ DE ÉTICA EM PESQUISA}

A tese de doutorado que deu origem a este artigo teve seu desenvolvimento aprovado pelo Comitê de Ética em Pesquisa, sob número de protocolo 1.775.897, C.A.A.E. número 56744716.7.0000.5016, em 14 de outubro de 2016.

\section{COMO CITAR - ABNT}

ANIC, Cinara Calvi. MARTINES, Elizabeth Antônia Leonel de Moraes. GONZAGA, Amarildo Menezes. Autobiografias docentes e a necessidade do retorno da voz feminina na formação de professores de Ciências. REAMEC - Rede Amazônica de Educação em Ciências e Matemática. Cuiabá, v. 9, n.3, e21100, set./dez., 2021. http://dx.doi.org/10.26571/reamec.v9i3.12782.

\section{COMO CITAR - APA}

Anic, C. C., Martines, E. A. L. De M., Golzaga, A. M. (2021). Autobiografias docentes e a necessidade do retorno da voz feminina na formação de professores de Ciências. REAMEC - Rede Amazônica de Educação em Ciências e Matemática, 9 (3), e21100. http://dx.doi.org/10.26571/reamec.v9i3.12782.

\section{LICENÇA DE USO}

Licenciado sob a Licença Creative Commons Attribution-NonCommercial 4.0 International (CC BY-NC 4.0). Esta licença permite compartilhar, copiar, redistribuir o manuscrito em qualquer meio ou formato. Além disso, permite adaptar, remixar, transformar e construir sobre o material, desde que seja atribuído o devido crédito de autoria e publicação inicial neste periódico.

\section{DIREITOS AUTORAIS}

Os direitos autorais são mantidos pelos autores, os quais concedem à Revista REAMEC - Rede Amazônica de Educação em Ciências e Matemática - os direitos exclusivos de primeira publicação. Os autores não serão remunerados pela publicação de trabalhos neste periódico. Os autores têm autorização para assumir contratos adicionais separadamente, para distribuição não exclusiva da versão do trabalho publicada neste periódico (ex.: publicar em repositório institucional, em site pessoal, publicar uma tradução, ou como capítulo de livro), com reconhecimento de autoria e publicação inicial neste periódico. Os editores da Revista têm o direito de proceder a ajustes textuais e de adequação às normas da publicação.

\section{PUBLISHER}

Universidade Federal de Mato Grosso. Programa de Pós-graduação em Educação em Ciências e Matemática (PPGECEM) da Rede Amazônica de Educação em Ciências e Matemática (REAMEC). Publicação no Portal de Periódicos UFMT. As ideias expressadas neste artigo são de responsabilidade de seus autores, não representando, necessariamente, a opinião dos editores ou da referida universidade.

\section{EDITOR}

Patrícia Rosinke (D) 0

\section{HISTÓRICO}

Submetido: 21 de julho de 2021.

Aprovado: 13 de outubro de 2021.

Publicado: 15 de dezembro de 2021. 